\title{
Examination of Liquor Amnii as a Method of Predicting Severity of Haemolytic Disease of Newborn
}

\author{
W. WALKER,* M.D. ; D. V. I. FAIRWEATHER, † M.B., M.R.C.O.G. \\ P. JONES, $\ddagger$ M.A., B.SC., PH.D.
}

Brit. med. F., 1964, 2, 141-147

The association of yellow amniotic fluid and hydrops foetalis has long been appreciated (Pickles, 1949), but only in recent years have attempts been made to predict the severity of haemolytic disease of the newborn by estimating the amount of bile pigment in liquor amnii during pregnancy. It is not known by what route bile pigment reaches the liquor, nor to what extent its level is dependent on other constituents or turnover rates, but this does not prevent an empirical evaluation of the clinical significance of pigment in liquor amnii.

Wild (1961) has suggested that in liquor as in cerebrospinal fluid (Stempfel and Zetterström, 1955) the bilirubin value is dependent on the protein level. Towards term the protein value in liquor amnii tends to fall and the bilirubin with it, so that Walker (1957) claimed that the bilirubin level was of prognostic value only before 35 weeks' gestation. Wild (1961), however, found that in severely affected cases protein and bilirubin often remained at high levels up to delivery.

In the present communication we report the results of haemoglobin, bilirubin, and protein estimations on liquor amnii and their role in predicting severe haemolytic disease of the newborn. For the latter purpose only results on specimens collected at 34-36 weeks' gestation are considered, partly because we do not know the pattern during normal pregnancies but also because it is at this stage that tests are likely to be of greatest use in indicating the need for premature induction.

\section{Material}

Liquor specimens from 277 immunized Rh-negative women were examined-83 during the 34 th week, 124 during the 35 th week, and 70 during the 36th week of gestation: 217 were obtained by paracentesis and 60 by artificial rupture of membranes performed to induce premature labour. Premature induction was performed only in patients who had had a previous very severely affected or stillborn infant, and this series contains a relative excess of such cases. The findings in the liquor amnii were not used to influence the conduct of any case.

The results in these cases were subsequently evaluated with the severity of disease in the foetus-sometimes directly with the cord haemoglobin and bilirubin values, but usually with the overall clinical picture according to the following classification :

Stillborn $=$ Stillborn with evidence of severe haemolytic disease of the newborn.

* Department of Child Health, University of Newcastle upon Tyne. † Department of Obstetrics, University of Newcastle upon Tyne.

$¥$ Department of Physical Chemistry, University of Newcastle upon
Very severe $=$ Cord haemoglobin less than 9 g./100 ml., or cord bilirubin over $7 \mathrm{mg} . / 100 \mathrm{ml}$., or overt very severe clinical disease at birth where cord blood values were not known.

Moderate =All other infants less severely affected but needing treatment.

Mild=Coombs-positive infants who did not require treatment. Rh-negative $=$ Unaffected infants.

In a few patients with a bad obstetric history amniocentesis was carried out at 32-33 weeks' gestation and in many others liquor was obtained by artificial rupture of the membranes at the time of delivery. Some of these cases have been used in the evaluation of different techniques in the examination of liquor amnii.

\section{Methods}

Five to ten millilitres of liquor amnii was obtained with a Drew Smythe catheter at the time of artificial rupture of the membranes or by abdominal paracentesis as described elsewhere (Fairweather and Walker, 1964). The specimen was placed in a sterile universal container, protected from daylight, and stored at $4^{\circ} \mathrm{C}$. until examined, usually within 12 hours of collection. Cloudiness, red cells, and other particulate matter were removed by Seitz filtration, using a Hemming filter, care being taken not to disturb any sedimented material when decanting the liquor. We had previously demonstrated that Seitz filtration did not remove bile pigment from liquor or serum.

Absorption spectra of liquor amnii for the range 360 to 630 $\mathrm{m} \mu$ were obtained by means of an Optica double-beam recording spectrophotometer using $0.5-\mathrm{cm}$. cells and distilled water as the blank (see Figs. 1-5).

Pigment can be identified in the spectra by characteristic absorption bands, but analysis is complicated if more than one pigment is present. Absorption bands most common in amniotic fluid had peaks at approximately 410, 450, 540, $580 \mathrm{~m} \mu$. Absorption at $450 \mathrm{~m} \mu$ was thought to be due to bilirubin and at the other wave-lengths to oxyhaemoglobin. Rarely, absorption also occurred in the $620-630 \mathrm{~m} \mu$ region. Examination with the Hartridge reversion spectrophotometer and the results of Schumm's test established that this pigment was methaemalbumin.

The tracings obtained show percentage absorption rather than optical density, so although the height of the peak is related to the quantity of pigment this relationship is logarithmic, not linear. Thus $10 \%$ absorption in the range zero to $10 \%$ absorption would give a peak in the tracing 10 times that produced by the same amount of pigment in the range 99$100 \%$ absorption. The effect of this is to minimize the degree of absorption at high levels of pigment and to exaggerate it at low levels. As most spectra produced less than 30\% absorption and as we were really concerned to recognize low levels of bilirubin, we feel that this visual representation was satisfactory. 
Figs. 1-5 illustrate our own assessment of particular curves. Haemoglobin was classified as,+++ , or +++ .

"Estimated" bilirubin was expressed in units, being the percentage difference between the observed curve and one drawn arbitrarily to omit the bilirubin band. The presence of haemoglobin in addition to bilirubin made this assessment difficult, but independent assessment by two observers rarely showed

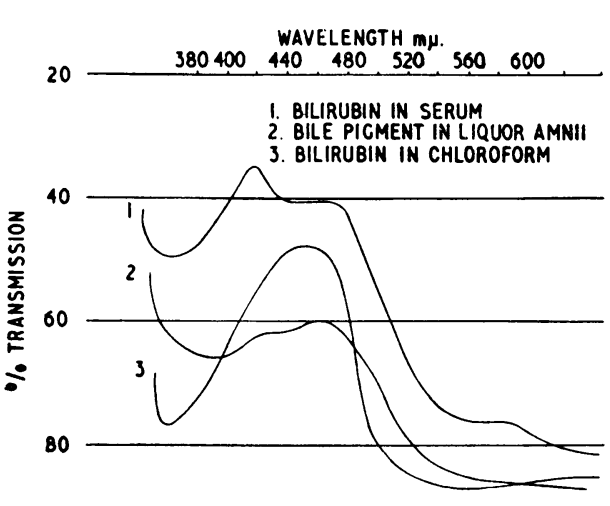

100

Fig. 1.- Spectrograph showing the similarity of absorption curves for icteric serum, liquor, and bilirubin in chloroform.

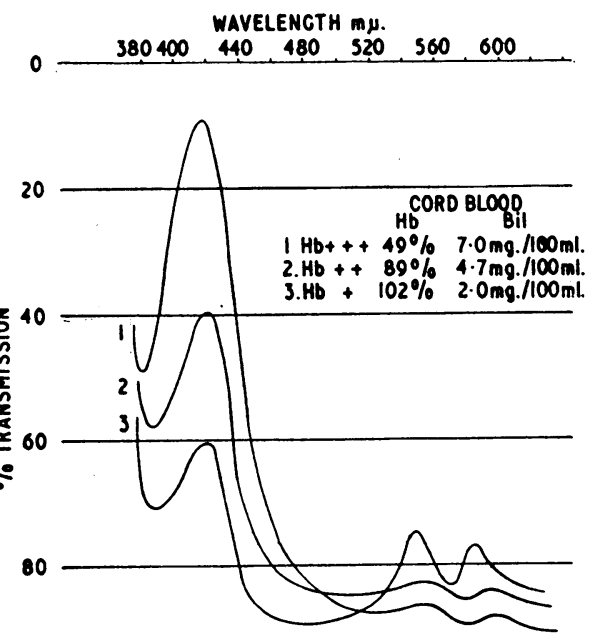

100

FIG. 2.-Illustrates the great variation in amount of haemoglobin observed in liquor amnii. Examples show correlation with severity of haemolytic disease of the newborn.

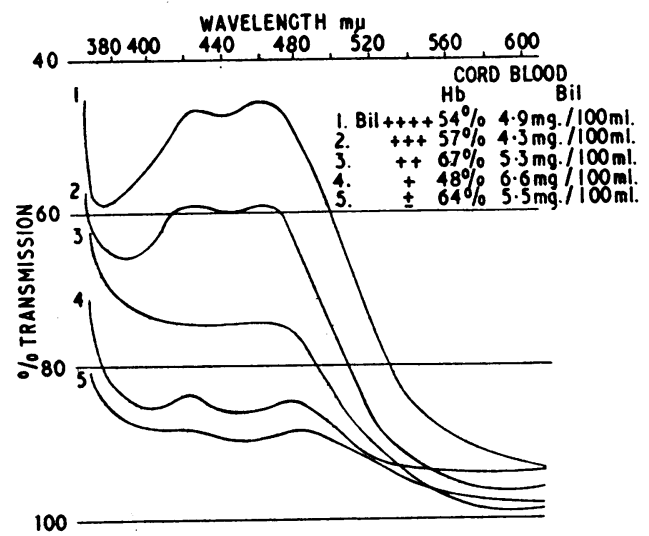

FIG. 3.-Illustrates different amounts of bilirubin in samples of liquor amnii which are almost free from haemoglobin. Despite the differences, all cases selected had haemolytic disease of the newborn of similar ted had haemolytic disease of the
severity. d if f e rences greater than \pm 3 units.

"Calculated" Bilirubin. - In an attempt to reach a more accurate evaluation of the spectra and to avoid errors due to cross-interference between absorption due to haemoglobin and that due to bilirubin we calculated the bilirubin level by means of two formulae. One, recommended by White et al. (1958), took into account optical densities at 575 and $455 \mathrm{~m} \mu$, and that devised by one of us (P.J.) used optical densities at 412 and 454 $\mathrm{m} \mu$. The values and significance of results by both methods were similar; therefore only results obtained by the latter method are detailed in this paper.

Chemical estimation of bili$\mathrm{rub}$ in $\mathrm{w}$ a $\mathrm{s}$ carried out on 100 samples of liquor amnii by the method of $\mathrm{K}$ ing a $\mathrm{nd}$ Coxon but using liquor rather than plasma. 1, 2 , or $3 \mathrm{ml}$. of liquor was used in the test, the amount of alcohol being varied so that the final volume was always $10 \mathrm{ml}$. Some samples were also tested by a modification of the Lathe-Ruthven technique using $3.6 \mathrm{ml}$. of liquor (Lathe, personal communication). Similar results were obtained by all methods.

Total protein values were determined in 298 specimens by the method of Folin and Ciocalteau (Papadopoulos et al., 1959).

\section{Bilirubin Levels in Liquor Amnii}

The bilirubin values as determined by the three methods are shown in Table I. Although there is a relation between the

TABLE I.-Estimated Bilirubin, Calculated Bilirubin (383 Cases), and Chemically Estimated Bilirubin (100 Cases) in Liquor Amnii

\begin{tabular}{|c|c|c|c|c|c|c|c|c|c|c|c|c|}
\hline \multirow{2}{*}{$\begin{array}{c}\text { Estimated } \\
\text { Bilirubin } \\
\text { (Units) }\end{array}$} & \multicolumn{7}{|c|}{$\begin{array}{c}\text { Calculated Bilirubin } \\
(\mathrm{mg} . / 100 \mathrm{ml} .)\end{array}$} & \multicolumn{5}{|c|}{$\begin{array}{c}\text { Chemically Estimated } \\
\text { Bilirubin* (mg./100 ml.) }\end{array}$} \\
\hline & $\leqslant 0.1$ & -0.2 & -0.3 & -0.5 & -1 & -2 & $>2$ & $\leqslant 0.15$ & -0.2 & -0.3 & -0.5 & $>0.5$ \\
\hline $\begin{array}{l}\mathrm{Nil} \\
1-10 \\
11-20 \\
21-30 \\
>30\end{array}$ & $\begin{array}{l}7 \\
= \\
-\end{array}$ & $\begin{array}{l}\frac{28}{z} \\
=\end{array}$ & $\begin{array}{r}53 \\
4 \\
- \\
-\end{array}$ & $\begin{array}{c}91 \\
37 \\
- \\
1\end{array}$ & $\begin{array}{l}35 \\
27 \\
13 \\
-\end{array}$ & $\begin{array}{r}14 \\
8 \\
13 \\
14 \\
3\end{array}$ & $\begin{array}{r}10 \\
7 \\
4 \\
4 \\
10\end{array}$ & $\begin{array}{r}7 \\
15 \\
3 \\
3 \\
2\end{array}$ & $\begin{array}{l}7 \\
8 \\
6 \\
4 \\
1\end{array}$ & $\begin{array}{r}4 \\
4 \\
12 \\
6 \\
2\end{array}$ & $\begin{array}{l}1 \\
1 \\
1 \\
2\end{array}$ & $\begin{array}{l}2 \\
1 \\
3 \\
1 \\
4\end{array}$ \\
\hline Total & 7 & 28 & 57 & 129 & 75 & 52 & 35 & 30 & 26 & 28 & 5 & 11 \\
\hline
\end{tabular}

* While in unselected material only $20 \%$ of cases had levels higher than 10 units, this is purposely the case for $50 \%$ of the present material.

bilirubin levels achieved by all three methods this is not precise. In particular, samples free from pigment as judged by the spectrograph gave a wide range of levels when estimated chemically, and vice versa. The calculated bilirubin value was always high if a pigment band was present in the spectrum, but high values were also obtained even when no absorption band was present.

None the less we have related the bilirubin value obtained by all methods to the severity of disease and find that the bilirubin estimated in units gives the best correlation. It is not necessary to present all the data, but two illustrative examples are given. (1) If we consider the 100 cases in which bilirubin was estimated chemically and compare severity in relation to a bilirubin level of greater or less than 0.2 mg. $/ 100 \mathrm{ml}$. and contrast

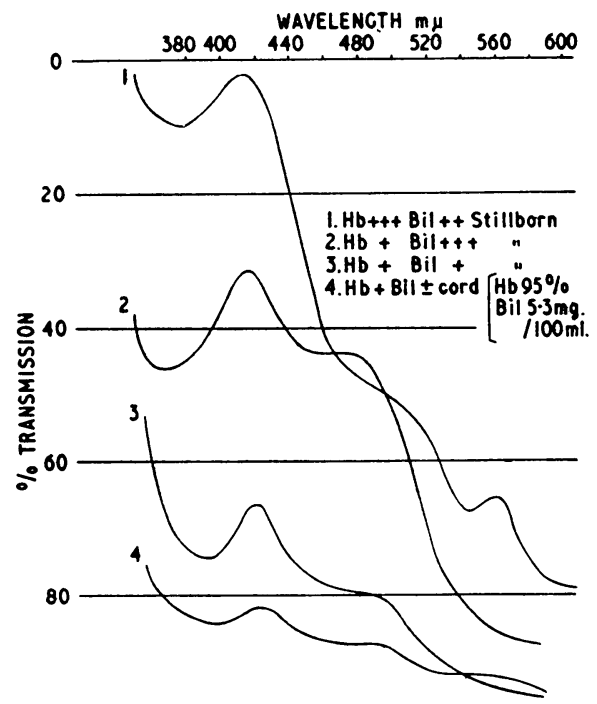

100

FIG. 4.-Illustrates the association of haemo the difficulty in measuring the amount of one pigment in the presence of another.
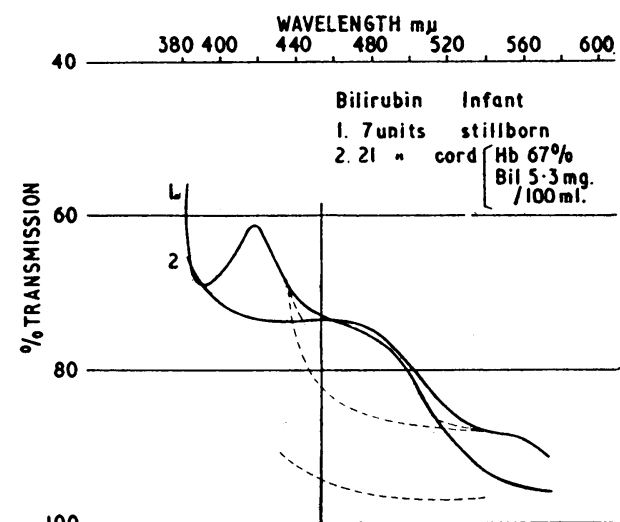

FIG. 5.-Illustrates the construction of an arbitrary line omiting the bilirubin band. globin and bilirubin in liquor amnii and indicates 
this with the same cases subdivided at a bilirubin value of 10 units, we find:

\begin{tabular}{|c|c|c|}
\hline $\begin{array}{c}\text { Stillbirth or } \\
\text { Very Severe Disease }\end{array}$ & $\begin{array}{l}\text { Less Severe Disease } \\
\text { or Rh-negative Infants }\end{array}$ & Bilirubin \\
\hline $\begin{array}{l}15 \\
30\end{array}$ & $\begin{array}{l}41 \\
14 \\
\end{array}$ & $\begin{array}{l}\leqslant 0.2 \mathrm{mg} .100 \mathrm{ml} . \\
>0.2 \stackrel{,}{ }\end{array}$ \\
\hline $\begin{array}{r}8 \\
37\end{array}$ & $\begin{array}{l}42 \\
13\end{array}$ & $\begin{array}{l}\leqslant 10 \text { units } \\
>10, y\end{array}$ \\
\hline
\end{tabular}

(2) With regard to calculated bilirubin and considering only cases with discrepant results, we find that of 21 cases with calculated values greater than $1 \mathrm{mg} . / 100 \mathrm{ml}$. but an estimated level of $<10$ units only one stillbirth occurred, two infants were severely affected, eight required treatment, but 10 were only mildly affected or Rh-negative.

\section{Protein Levels in Liquor Amnii}

In Table II the protein level is shown in relation to the bilirubin level estimated in units. High bilirubin levels tend to be associated with high protein levels, but there are many exceptions.

\begin{tabular}{|c|c|c|c|c|c|c|c|c|}
\hline \multirow{2}{*}{$\begin{array}{c}\text { Bilirubin } \\
\text { Units }\end{array}$} & \multicolumn{7}{|c|}{ Protein (mg./100 ml.) } & \multirow{2}{*}{ Total } \\
\hline & $1-50$ & $51-100$ & $101-200$ & $201-300$ & $301-500$ & $501-800$ & $>800$ & \\
\hline $\begin{array}{c}\mathrm{Nil} \\
1-10 \\
11-20 \\
21-30 \\
>30\end{array}$ & $\frac{18}{1}$ & $\begin{array}{r}42 \\
9 \\
= \\
-\end{array}$ & $\begin{array}{r}86 \\
44 \\
6 \\
2 \\
-\end{array}$ & $\begin{array}{r}21 \\
17 \\
8 \\
2 \\
-\end{array}$ & $\begin{array}{l}4 \\
4 \\
6 \\
5 \\
2\end{array}$ & $\bar{z}$ & $\begin{array}{l}1 \\
1 \\
2 \\
6\end{array}$ & $\begin{array}{r}172 \\
75 \\
21 \\
18 \\
12\end{array}$ \\
\hline Total & 19 & 51 & 138 & 48 & 21 & 11 & 10 & 298 \\
\hline
\end{tabular}

When 215 samples collected at 34-36 weeks alone were considered we found that the protein level correlated less well with severity than did the estimated bilirubin value. The best discrimination was achieved at a protein level of $200 \mathrm{mg} . / 100$ $\mathrm{ml}$. However, in 61 pregnancies associated with values greater than this the resulting haemolytic disease was 15 stillborn, 11 very severe, 16 moderate, 10 mild, and $9 \mathrm{Rh}$-negative, so that predictions based on this are as likely to be wrong as to be correct.

If 32 cases are considered where the findings conflicted in that the bilirubin was $<10$ units but the protein value over $200 \mathrm{mg}$. $/ 100 \mathrm{ml}$., six pregnancies resulted in stillbirth or very severe disease whereas nine infants were Rh-negative.

We therefore concluded that the protein level in liquor amnii does not enable as good an estimate of severity of haemolytic disease as is possible from the estimated bilirubin value.

Estimation of the bilirubin in units is superior to any of the other methods, and further considerations are based solely on the significance of bilirubin estimated in this way.

\section{Significance of Bilirubin in Liquor Amnii}

Initially we considered the results at 34,35 , and 36 weeks separately, but, as little difference was apparent, believe it justifiable to combine them in one large group.

In Table III the relation between bilirubin level and severity of haemolytic disease in the foetus is shown. Half of the specimens were completely free from bilirubin and in many of the others the amount present was small. Only $55(20 \%)$ out of 277 contained more than 10 units of pigment, and this is clearly but not precisely related to the severity of disease. When the bilirubin level was over 10 units no infant was $\mathrm{Rh}$-negative and mild disease was exceptional, but in $24 \%$ of such cases disease of only moderate severity occurred. Even when bilirubin levels were above 20 units $4(12 \%)$ out of 32 cases were not very severely affected. At the other extreme, among 141 patients with clear liquor stillbirth occurred on four occasions and very severe disease on 12 more ( $11 \%$ combined). Of 81 cases with bilirubin values of $1-10$ units, $28 \%$ resulted in stillbirth or very severe disease and $31 \%$ in Rh-negative or mildly affected infants.

TABLE III.-Bile Pigment in Liquor Amnii at 34-36 Weeks' Gestation in

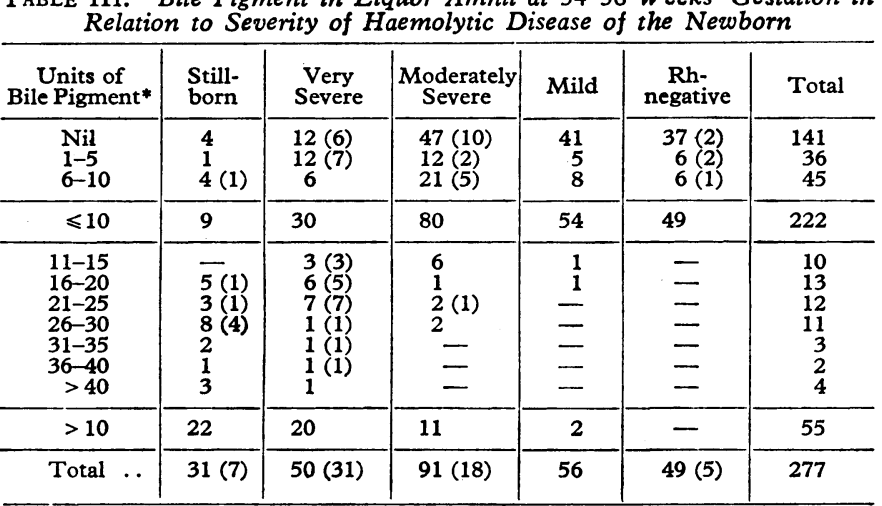

- Figures in parentheses represent cases induced because of a bad obstetric history.

As the principal use of liquor examination is likely to be in selecting patients for premature induction one can assess its value by classifying as "successful" those cases where the presence of pigment was associated with stillbirth or very severe disease, or where clear liquor was associated with at most only moderate disease. The combination of the stillborn and the very severely affected as one group is justified because $60 \%$ of the very severely affected infants in this material had been induced prematurely and several would otherwise undoubtedly have been stillborn.

With this consideration we found that a bilirubin level greater than 15 units successfully predicted stillbirth or very severe disease in over $80 \%$ of cases while clear liquor predicted less severe disease with almost $90 \%$ success. With a level from 1 to 15 units prediction of stillbirth or very severe disease was successful in only $20-40 \%$ of cases.

Liquor examination does not enable perfect selection of cases for premature induction, but the best discrimination is achieved at a bilirubin level of 10 units. Above this level $20 \%$ of cases would be selected. Of these, over $75 \%$ resulted in stillbirth or very severe disease, but although all $\mathrm{Rh}$-negative infants would have been excluded two mildly affected infants would have been selected. Thirty-nine ( $48 \%$ ) of the very severely affected or stillborn infants would have been missed, and it should be emphasized that even completely clear liquor on more than one occasion during pregnancy did not exclude the possibility of stillbirth.

So far we have been concerned chiefly to demonstrate a relation between the bilirubin level in amniotic fluid and the likelihood of stillbirth or very severe disease. However, there may be a relation throughout the full range of severity, and to test this we have in Tables IV and V related the liquor bilirubin level to the cord haemoglobin and bilirubin values. These were available only for live-born cases.

TABLE IV.-Relation Between Bilirubin in Liquor Amnii and Cord Haemoglobin of the Infant in 192 Cases

\begin{tabular}{|c|c|c|c|c|c|c|c|}
\hline \multirow{2}{*}{$\begin{array}{c}\text { Bilirubin } \\
\text { in } \\
\text { Liquor } \\
\text { Amnii }\end{array}$} & \multicolumn{6}{|c|}{ Cord Haemoglobin (g./100 ml.) } & \multirow{2}{*}{$\begin{array}{c}\text { Mean } \\
\mathrm{Hb} \\
(\mathrm{g} . / \\
100 \mathrm{ml} .)\end{array}$} \\
\hline & $<9$ & $9-12$ & $\begin{array}{c}12 \cdot 1- \\
14 \cdot 8\end{array}$ & $\begin{array}{l}14 \cdot 9- \\
17 \cdot 7\end{array}$ & $>17 \cdot 7$ & Total & \\
\hline${ }_{1-10}$ units. & $\begin{array}{r}9 \\
13\end{array}$ & $\begin{array}{r}8 \\
21\end{array}$ & $\begin{array}{l}35 \\
16\end{array}$ & $\begin{array}{l}33 \\
11\end{array}$ & $\begin{array}{r}12 \\
2\end{array}$ & $\begin{array}{l}97 \\
63\end{array}$ & $\begin{array}{l}14 \cdot 2 \\
11 \cdot 8\end{array}$ \\
\hline $\begin{array}{ccc}11-20 & \text { units } & . \\
21-30 & \Rightarrow & . \\
>30 & \Rightarrow & \end{array}$ & $\begin{array}{l}6 \\
8 \\
2\end{array}$ & $\begin{array}{r}6 \\
3 \\
-\end{array}$ & $\begin{array}{l}4 \\
1 \\
-\end{array}$ & $\frac{2}{-}$ & E & $\begin{array}{r}18 \\
12 \\
2\end{array}$ & \begin{tabular}{r|}
10.7 \\
8.0 \\
8.2
\end{tabular} \\
\hline
\end{tabular}


TABle V.-Relation Between Bilirubin in Liquor Amnii and Cord Bilirubin of Infant in 193 Cases

\begin{tabular}{|c|c|c|c|c|c|c|c|}
\hline \multirow{2}{*}{\multicolumn{2}{|c|}{$\begin{array}{c}\text { Bilirubin } \\
\text { in Liquor } \\
\text { Amnii }\end{array}$}} & \multicolumn{5}{|c|}{ Cord Bilirubin (mg./100 ml.) } & \multirow{3}{*}{$\begin{array}{c}\text { Mean } \\
\text { Bil. (mg./ } \\
100 \mathrm{ml} .)\end{array}$} \\
\hline & & $<2$ & $2-3$ & $3 \cdot 1-5$ & $>5$ & Total & \\
\hline$\underset{1-10}{\mathrm{Nil}}$ units & $\begin{array}{l}. \\
\cdots\end{array}$ & $\begin{array}{r}19 \\
5\end{array}$ & $\begin{array}{l}29 \\
12\end{array}$ & $\begin{array}{l}31 \\
29\end{array}$ & $\begin{array}{l}19 \\
18\end{array}$ & $\begin{array}{l}98 \\
64\end{array}$ & \\
\hline $\begin{array}{l}11-20 \text { units } \\
21-30 \quad \text { " } \\
>30 \quad\end{array}$ & $\ddot{\ldots}$ & $\underline{1}$ & $\underline{2}$ & $\begin{array}{l}6 \\
3 \\
1\end{array}$ & $\begin{array}{l}9 \\
8 \\
1\end{array}$ & $\begin{array}{r}18 \\
11 \\
2\end{array}$ & $\begin{array}{l}5 \cdot 0 \\
5 \cdot 6 \\
4 \cdot 8\end{array}$ \\
\hline
\end{tabular}

Bilirubin in liquor amnii is related both to cord haemoglobin and to bilirubin levels and is not closer to one than to the other. However, clear liquor can occur with all values of cord haemoglobin or bilirubin, and it is of interest that high cord bilirubin values were associated with all levels of bilirubin in liquor.

We have indicated the difficulty in evaluating the significance of pigment when values for normal pregnancies are not established. In the present material were $49 \mathrm{Rh}$-negative pregnant women, while we have examined liquor for six additional Rhnegative pregnant women before 34 weeks' gestation and 10 "normal" patients in whom hysterotomy was performed for some coincidental reason. No cases with intrauterine death are included. The findings are summarized in Table VI. All told, bilirubin was recognized in 20 out of 65 cases, but the highest value recorded was 9 units. Before 34 weeks it was present in half of the cases, but at 34-36 weeks in only a quarter.

TABLE VI.-Bilirubin in Liquor Amnii of 65 Normal Patients Related to Gestation

\begin{tabular}{|c|c|c|c|c|c|c|}
\hline \multirow{2}{*}{\multicolumn{2}{|c|}{ Bilirubin }} & \multicolumn{4}{|c|}{ Gestation (Weeks) } & \multirow{2}{*}{ Total } \\
\hline & & $<20$ & $20-30$ & $31-33$ & $34-36$ & \\
\hline${ }_{1-10}^{\mathrm{Nil}}$ units & $\therefore$ & $\begin{array}{l}2 \\
1\end{array}$ & $\overline{1}$ & $\begin{array}{l}3 \\
3\end{array}$ & $\begin{array}{l}40 \\
15\end{array}$ & $\begin{array}{l}45 \\
20\end{array}$ \\
\hline
\end{tabular}

Bilirubin was estimated chemically in 25 " normal liquors." The range was $0.1-0.27 \mathrm{mg} . / 100 \mathrm{ml}$, but in 22 out of the 25 the level was less than $0.15 \mathrm{mg} . / 100 \mathrm{ml}$.

\section{Significance of Haemoglobin in Liquor Amnii}

Haemoglobin was detected in $60 \%$ of all samples of liquor amnii, but the amount was gross in only $10 \%$, made up of 11 out of 60 artificial rupture of membranes specimens and of only 16 out of 217 paracentesis specimens, suggesting that haemoglobin of maternal origin was often a contaminant. That the haemoglobin was usually maternal was supported by the results of Singer's alkali denaturation test and the spectrograph of carboxyhaemoglobin in the $290 \mathrm{~m} \mu$ region, while in some cases erythrocytes of the same $\mathrm{ABO}$ and $\mathrm{Rh}$ group as the mother were demonstrated in liquor. In others the results were equivocal, but in four a small quantity of almost pure blood was obtained at paracentesis, and this was shown to be Rh-positive Coombs-positive, and therefore from the foetus.

The presence of haemoglobin has been related to the severity of haemolytic disease in the foetus. High haemoglobin levels were associated with all degrees of severity but were commonest in association with stillbirth and very severe disease. However, the absence of haemoglobin did not exclude the possibility of severe disease, for in $68 \%$ of such cases no haemoglobin was detected.

Therefore, considered alone, the presence of or absence of haemoglobin does not provide a reliable method of predicting or excluding severe disease.

\section{Significance of Haemoglobin Together with Bilirubin in Liquor Amnii}

We have noted a relation between bilirubin in liquor amnii and the severity of disease in the foetus and a possible associa- tion between high levels of haemoglobin and stillbirth. In Table VII we have shown the relation between haemoglobin and bilirubin in liquor. There is no direct correlation. At all values of haemoglobin all levels of bilirubin are observed. It is unlikely, therefore, that both arise from the same sources nor does the presence of haemoglobin lead to increase in bilirubin. Even where liquor samples were heavily contaminated with haemoglobin, further specimens a few days later did not show any significant increase in the bilirubin level, and we observed cases where absolutely clear liquor was obtained two weeks after a heavily blood-stained specimen. It is possible that very high levels of both haemoglobin and bilirubin may signify very serious disease, but it is doubtful if the combined significance is any greater than that of a high level of bilirubin per se.

TABLE VII.-Haemoglobin in Relation to Bilirubin in Liquor Amnii

\begin{tabular}{c|c|c|c|c|c|c}
\hline \multirow{3}{*}{ Haemoglobin } & \multicolumn{5}{|c|}{ Bilirubin } & Total \\
\cline { 2 - 5 } & +++ & ++ & + & \pm & Nil & \\
\hline+++ & 2 & 4 & 3 & 8 & 9 & 26 \\
++ & 3 & 4 & 2 & 4 & 16 & 29 \\
+ & 13 & 11 & 24 & 21 & 39 & 108 \\
Nil & 7 & 11 & 22 & 9 & 65 & 114 \\
\hline Total & 25 & 30 & 51 & 42 & 129 & 277 \\
\hline
\end{tabular}

\section{Significance of Methaemalbumin in Liquor Amnii}

Methaemalbumin recognized by an absorption band at 630 $\mathrm{m} \mu$ and confirmed by Schumm's test was present in only 11 of the samples of liquor amnii tested. In all of these haemoglobin and bilirubin were also present, often in high levels. One would therefore expect an association with severe disease, and this is borne out by the finding that 9 out of the 11 pregnancies resulted in stillbirth. However, it should be pointed out that not all foetuses were dead at the time of amniocentesis, the foetal heart being clearly audible in at least four.

Two infants, indeed, were born alive. One-birth weight 4 lb. 7 oz. $(2,015$ g.), cord haemoglobin 8 g. $/ 100 \mathrm{ml}$., cord bilirubin $6.1 \mathrm{mg} . / 100 \mathrm{ml}$.-was hydropic, and although exchange transfusion was completed and the ascites aspirated, it died a few hours later. Methaemalbumin was present in the cord blood of this infant. The other was only moderately affectedcord haemoglobin $16 \mathrm{~g} . / 100 \mathrm{ml}$., cord bilirubin $4.3 \mathrm{mg} . / 100 \mathrm{ml}$. -and survived after exchange transfusion. Unfortunately the cord blood was not examined for methaemalbumin.

The presence of methaemalbumin in liquor amnii is ominous but does not necessarily indicate intrauterine death; nor, conversely, does its absence exclude hydrops foetalis.

Methaemalbumin was detected in the liquor at 36 weeks of one "normal" case. Haemoglobin and bilirubin were also present. The foetus was anencephalic, and was dead at the time of liquor examination.

\section{Discussion}

During the period 1952-61, in the Newcastle hospitals, 1,633 infants with haemolytic disease of the newborn were born alive and $96.3 \%$ survived. During the same period 2,609 cases of haemolytic disease of the newborn occurred in Northumberland and Durham and $14 \%$ were stillborn. Although problems still exist, particularly with regard to the management of infants born in extremis or developing hyperbilirubinaemia despite early exchange transfusion, the chief problem is the prevention of stillbirth.

So far the only accepted treatment is induction of premature labour before intrauterine death has occurred. Mollison (1956) has questioned whether severity of disease in liveborn infants is significantly diminished by premature induction, and as 
induction is potentially dangerous to the mother and prematurity a major hazard for any newborn infant, cases should be selected for induction only where stillbirth is "inevitable" and delayed as late in pregnancy as is compatible with live birth.

Our aim is to predict stillbirth together with "very severe" disease because we do not think it possible to be more specific and consider that the most severely affected liveborn infants would benefit from early delivery. We see little purpose in trying to forecast finer degrees of severity such as the probability of kernicterus or whether anaemia will develop in the first week or later. Such predictions (Bevis, 1950, 1956; Walker, 1957 ; Liley, 1961 ; Walker and Jennison, 1962) are not relevant to antenatal management, and selection for early exchange transfusion is made better on haematological and clinical grounds at birth rather than on antenatal forecasts. Three methods of forecasting severity are in common use: maternal antibody titre, previous obstetric history, and examination of liquor amnii, although other methods such as enzyme and erythropoietin assays are being studied (Beecham et al., 1962 ; Goodlin, 1962 ; Halvorsen and Finne, 1963).

Maternal antibody titrations are difficult to standardize (Parkin et al., 1961) and although correlated with severity are difficult to interpret in the individual case, especially if one seeks to restrict induction to cases where stillbirth is almost inevitable.

In families where a previous infant has been stillborn or very severely affected there is a $60 \%$ risk that any subsequent $\mathrm{Rh}-$ positive foetus will be stillborn (Walker and Murray, 1956). Induction in such families will prevent some stillbirths (Walker et al., 1957) at the cost of unnecessary induction of other patients, and this is especially true if the father is heterozygous. Study of Table II will reveal certain limitations of the family history as a method of selecting patients for premature induction. Of the 61 so selected five infants were $\mathrm{Rh}$-negative while 18 were only moderately affected, but it is possible that severity had been modified by induction. Only 38 out of 81 very severely affected or stillborn cases were identified by the previous history, a proportion similar to that picked up by a liquor bilirubin value of over 10 units. It seems possible that if family history and liquor examination were combined, improved selection might be achieved, especially in families where the father is heterozygous, for in these the choice rests essentially between severe disease and a normal infant. Also in families with a bad obstetric history examination of liquor perhaps of more than one specimen might help to select the optimal time for induction. However, stillbirths do occur in pregnancies preceded by less severe disease and even in patients developing antibodies in a current pregnancy. Finally, before the family history as a criterion for induction can be applied the family must suffer a very severely affected infant, and, this having occurred, the prospect of successful induction is diminished because the worse the obstetric history the earlier intrauterine death is likely to occur (Walker, 1960).

In the light of present knowledge it would appear that some of the earlier observations on liquor amnii were incorrect. Bevis (1950) reported that the van den Bergh reaction was negative even in yellow liquor and (Bevis, 1952) that neither the icterus index nor the bilirubin level was of prognostic value. He considered that the haemoglobin, non-haematin iron, and urobilinogen content of liquor were most clearly correlated with severity of disease. Currently, however, most workers consider that the bilirubin level is of most help, and, although this can be estimated chemically, values are low ; we agree with Mackay (1961) and Walker and Jennison (1962), however, that the significance of bilirubin is more readily appreciated by inspection of the spectral absorption curve at a wavelength of $450 \mathrm{~m} \mu$. This absorption is almost certainly due to bilirubin because it is similar to that obtained with icteric sera and crystalline bilirubin refluxed in chloroform (Fig. 1). Moreover, yellow liquor treated with diazotized sulphanilic acid gives colour changes characteristic of bilirubin and the yellow pigment moves with albumin on electrophoresis.

The source of bilirubin in liquor amnii is not established. Theoretically, it could derive from mother or foetus, but as the pigment is mainly unconjugated it is probably from the foetus, for if from the mother a concentrating mechanism would have to be postulated to account for some of the high values observed. The actual level may depend on the albumin level, and as this tends to fall towards the end of pregnancy a secondary fall in bilirubin might follow (Wild, 1961). However, this does not mean that bilirubin enters liquor amnii attached to protein and must therefore share a common source. Indeed, there is no agreement concerning the origin of liquor protein ( $\mathrm{McKay}$ et al., 1958 ; Bangham et al., 1958 ; Abbas and Tovey, 1960 ; Oram, 1960; Brzezinski et al., 1961 ; Derrington and Soothill, 1961 ; Dancis et al., 1961 ; Viergiver et al., 1962), but passage is not dependent solely on molecular size, for the foetal level of diphtheria antitoxin may be twice that of the mother (Davies, 1960).

We would postulate that bilirubin enters liquor amnii by diffusion through the mucosa of the respiratory or upper alimentary tract and that the level reached is determined partly by the bilirubin level in the infant and partly by the level of albumin in the amniotic fluid. We base this on our observation that if icteric sera or amniotic fluid is ultrafiltered the filtrate contains no bilirubin if the membrane is surrounded by air, water, or saline, but, if immersed in reconstituted human albumin, bilirubin crosses the membrane roughly in proportion to the amount of available albumin. The level of bilirubin in liquor may be maintained despite rapid turnover rates, for, although water may have a turnover time of three hours and sodium 14 hours (Davies, 1960 ; Bourne, 1962), that for protein may be much longer (Villee, 1957 ; Bangham et al., 1958). Wild (1961) showed that when the foetus was hydropic the protein and bilirubin levels were maintained throughout the latter weeks of pregnancy. A possible explanation for this is that in such cases capillary permeability is increased to an extent such as to allow free passage of protein/bilirubin complex, for we have observed that in hydrops foetalis the protein and bilirubin levels in ascitic fluid may be similar to those in serum.

Gairdner et al. (1950) suggested that yellowish-green pigment in liquor amnii came from meconium but did not demonstrate correlation between the degree of meconium staining and the bilirubin level, while Bevis (1950) obtained negative tests for bilirubin in specimens of liquor containing mecon:um. We have found that a mixture of meconium and liquor incubated at $37^{\circ} \mathrm{C}$. for periods up to two weeks developed absorption in the $420 \mathrm{~m} \mu$ but little in the $450 \mathrm{~m} \mu$ region. Extracts of meconium in water, saline, and alcohol gave little absorption at $450 \mathrm{~m} \mu$ but extraction in chloroform did so. Twenty samples of liquor collected near term were heavily contaminated with meconium ; after filtration all contained haemoglobin but only 13 contained bilirubin, the level of which was no higher than expected if one took into account the severity of disease in the infant.

Uncertainties concerning the origin of bilirubin do not invalidate an empirical assessment of its significance provided conditions are standardized. Walker (1957) found that observations after 35 weeks' gestation were unreliable, mainly because of the disappearance of bilirubin, but reported occasional high results at 37 weeks and the presence of pigment at 34 weeks in normal pregnancy. Mayer et al. (1961) thought that pigment present at 28 weeks might be of no significance, but later, even after 35 weeks, was of prognostic value, a view shared by Liley (1961). None the less we have based our conclusions only on samples examined at 34-36 weeks' gestation because such timing is likely to be of most practical value and we felt that repeated routine testing from 32 weeks as recommended by Walker (1957) was not justified. 
The best discrimination was achieved at a bilirubin level of 10 units, and this is also the highest value that we have observed in normal pregnancy.

Values over 10 units were found in $20 \%$ of samples, and $40 \%$ of these resulted in stillbirth and $36 \%$ in very severe disease, but $4 \%$ required no treatment at all. Several patients with a bad obstetric history had been induced prematurely, otherwise the proportion stillborn might have been much higher. On the debit side, $29 \%$ of all stillbirths and $60 \%$ of all very severely affected infants were associated with bilirubin levels of less than 10 units. It appears, therefore, that at 34-36 weeks' gestation a bilirubin value of more than 10 units indicates a high risk of severe disease and is an indication for premature induction, while levels lower than this give only partial reassurance.

Some patients with a bilirubin level of less than 10 units had been induced because of a bad obstetric history. One stillbirth occurred in this group, but it is tempting to suggest that a bilirubin level of less than 10 units may enable one to recognize patients where live birth is probable even though a previous infant has been very severely affected.

Mackay (1961) in a similar study, although not restricted to 34-36 weeks' gestation, found bilirubin grades 3, 4, and 5 (which would appear to correspond with over 10 units on our classification) in $23 \%$ of cases ; $53 \%$ resulted in stillbirth or very severely affected infants, compared with $75 \%$ in our series. $\mathrm{He}$ stated that liquor examination together with other data indicated the optimal time for intervention; but this does not seem to be justified by his data, and it seems dangerous to leave for a further two to three weeks patients who at 34 weeks' gestation already have considerable pigment in the liquor. Liley (1961) examined two specimens of liquor at intervals of two to three weeks and claimed to predict three grades of severity-mild or unaffected, very severe or stillbirth, and an intermediate group. He also found that the bilirubin level in liquor was closely related to that in cord blood but not to the cord haemoglobin values, whereas we found correlation with both. Although he felt that in many cases the liquor findings merely confirmed expectation based on the previous history, occasional surprise findings made the investigation worth while. Mayer et al. (1961) concluded that the main value of liquor examination was in predicting stillbirth or very severe disease, especially in cases where the father was heterozygous, and felt that the slight additional information obtained did not justify repeated examination. Walker and Jennison (1962), however, claimed to forecast severity precisely in $91 \%$ of all cases and in $98.6 \%$ of certain groups.

Other pigments sometimès found in liquor amnii are of less prognostic value than bilirubin. Haemoglobin probably often of maternal origin was present in $60 \%$ of our cases but in only $5 \%$ of those of Walker and Jennison (1962). Neither they nor us nor Liley (1961) observed close correlation with severity of disease in the foetus. A possible association with hydrops foetalis may be due to injury to the large placental site common in such cases.

The presence of methaemalbumin was encountered too infrequently to provide a significant contribution to management, and although indicative of very severe disease and an indication for urgent delivery did not establish intrauterine death as suggested by Liley (1961) and Walker and Jennison (1962). Errors in liquor examination during pregnancy occur (Hyslop and Whiley, 1960; Liley, 1963), while amniocentesis may have dangers both for the present (Mayer et al., 1961) or subsequent pregnancies.

Zipursky et al. (1963) established that bleeding from the foetus into the mother occurred in some cases. Hibbard (1963) suggested that amniocentesis might lead to a succession of stillbirths in certain families, but we (Fairweather et al., 1963) found little evidence to support this hypothesis.

\section{Conclusion}

The examination of liquor amnii during pregnancy in Rh-negative women with antibodies will provide a means of forecasting stillbirth or very severe disease in at best $50 \%$ of cases. Such examination is indicated particularly in patients in whom premature induction is being considered because of other reasons-for example, a previous history of stillbirth or very severe disease-and may be of special value in families where the father is heterozygous, because other methods of establishing the $\mathrm{Rh}$ group of the foetus have not proved satisfactory. Witebsky and Mohn (1945) and Witebsky (1948) claimed to have detected $\mathrm{Rh}$-soluble substance in liquor amnii, but we (Walker and Bailey, 1956) could not confirm this, nor more recently have Lawler and Shatwell (1962). The Rh grouping of epithelial cells has not proved satisfactory in our hands.

Repeated examination may be indicated in families with a bad obstetric history in order to decide how late in pregnancy it is safe to delay induction, but it is doubtful whether this is justified in all cases unless there is some other indication of severe disease. However, it should be taken into account that, whereas induction at 35 weeks will prevent $50 \%$ of stillbirths in families with a history of one previous stillbirth or very severely affected infant, it must be performed at 32 weeks to achieve similar success in patients who have had more than one previous pregnancy that has ended in this way. On the other hand, similar results could be achieved by induction at 37 weeks in patients who had a less severe history or who had developed antibodies in the current pregnancy (Walker, 1960). In this context it is emphasized that the bilirubin level in liquor amnii does not usually fall even as term is approached if the foetus is very severely affected (Wild, 1961).

Before deciding on a policy with regard to amniocentesis during pregnancy as a means of forecasting the severity of haemolytic disease of the newborn one must take into account both the possible value and the danger of the procedure in the particular case. The operation should be carried out by a senior person, and great care should be taken to avoid injury to the placental site.

\section{Summary}

Liquor amnii specimens from immunized $\mathrm{Rh}$-negative mothers were examined for the presence of bilirubin, protein, and haemoglobin. It was found that the amount of bilirubin present was best evaluated by assessment of the spectrum. This was arbitrarily expressed in units.

The significance of these constituents of liquor as a method of forecasting severity of haemolytic disease of the newborn was considered in 277 patients examined at 34-36 weeks' gestation.

It was felt that the amount of bilirubin present provided the best prognostic information.

Levels of over 10 units were found in $20 \%$ of all cases, and $40 \%$ of these resulted in stillbirth and $36 \%$ in very severe disease.

However, very severe disease also occurred in patients whose liquor bilirubin level was less than this. In fact, stillbirth occurred in 3\% and very severe disease in $9 \%$ of patients in whom the liquor was absolutely clear.

The examination of liquor amnii does not enable perfect selection of cases for premature induction to be made, but, particularly in conjunction with the previous history, is of great practical value in the management of haemolytic disease of the newborn.

The need to evaluate the potential benefits and risks of the procedure in individual cases is emphasized.

As usual we are indebted to the medical and nursing staffs in the Princess Mary Maternity Hospital and General Hospital, Newcastle 
upon Tyne, for their co-operation; to Miss D. Purvis and Mrs. A. Hauxwell for the majority of the analyses; to Dr. T. R. C. Boyde for identifying the methaemalbumin ; and to Mrs. M. Malaghan for secretarial assistance. Dr. S. M. Murray, of the Regional Blood Transfusion Centre, has taken an interest in the study throughout and given much helpful advice, especially in the preparation of this report.

\section{REFERENCES}

Abbas, T. M., and Tovey, J. E. (1960). Brit. med. 7., 1, 476.

Bangham, D. R., Hobbs, K. R., and Terry, R. J. (1958). Lancet, 2, 351. Beecham, C. T., Molthan, L., Boutwell, J., and Rohrbeck, C. W. (1962). Amer. F. Obstet. Gynec., 83, 1053.

Bevis, D. C. A. (1950). Lancet, 2, 443.

(1952). Ibid., 1, 395.

- (1956). 7. Obstet. Gynaec. Brit. Emp., 63, 68

Bourne, G. L. (1962). The Human Amnion and Chorion. Lloyd-Luke, London.

Brzezinski, A., Sadovsky, E., and Shafrir, E. (1961). Amer. F. Obstet. Gynec., 82, 800 .

Dancis, J., Lind, J., Oratz, M., Smolens, J., and Vara, P. (1961). Ibid., 82, 167.

Davies, J. (1960). Survey of Research in Gestation and the Developmental Sciences. Williams and Wilkins, Baltimore.

Derrington, M. M., and Soothill, J. F. (1961). F. Obstet. Gynaec. Brit. Cwlth, 68, 755 .

Fairweather, D. V. I., Murray, S., Parkin, D., and Walker, W. (1963). Lancet, 2, 1190 .

and Walker, W. (1964). F. Obstet. Gynaec. Brit. Cwlth, 71, 48. Gairdner, D., Lawrie, N. R., and Hutcheon, M. (1950). Lancet, 2, 541. Goodlin, R. C. (1962). West. F. Surg., 70, 181.

Halvorsen, S., and Finne, P. H. (1963). Brit. med. F., 1, 1132.

Hibbard, B. M. (1963). Lancet, 2, 642.
Hyslop, R. S., and Whiley, W. (1960). Med. F. Aust., 1, 622.

Lawler, S. D., and Shatwell, H. S. (1962). Vox Sang., 7, 488.

Liley, A. W. (1961). Amer. F. Obstet. Gynec., 82, 1359.

(1963). Ibid., 86, 485 .

McKay, D. G., Richardson, M. V., and Hartig, A. T. (1958). Ibid., 75, 699.

Mackay, E. V. (1961). Aust. N.Z. 7. Obstet. Gynaec., 1, 78.

Mayer, M., Gueritat, P., Ducas, P., and Lewi, S. (1961). Presse méd.,

69, 2493.
Mollison, P. L. (1956). Blood Transfusion in Clinical Medicine, p. 478. Blackwell, Oxford.

Oram, W. J. (1960). N.Z. med. F., 59, 255.

Papadopoulos, N. M., Hess, W. C., O'Doherty, D., and McLane, J. E. (1959). Clin. Chem., 5, 569.

Parkin, D., Murray, S., and Walker, W. (1961). International Investigation of $\mathrm{Rh}$ Antibody Titrations : report to participants.

Pickles, M. M. (1949). Haemolytic Disease of the Newborn. Blackwell, Oxford.

Stempfel, R., and Zetterström, R. (1955). Pediatrics, 16, 184

Viergiver, E., Stroup, P. E., Sheff, M. F., and Westphal, M. (1962). Obstet., Stroup, P. E., Sh.

Villee, C. A. (1957). Gestation. Transactions of 4th Conference Josiah Macy Jr. Foundation, New York.

Walker, A. H. C. (1957). Brit. med. f., 2, 376

and Jennison, R. F. (1962). Ibid., 2, 1152.

Walker, W. (1960). Proc. 7 th Congr. Europ. Soc. Haemat. London, 1959, Part II, p. 1186.

and Bailey, B. M. (1956). F. clin. Path., 9, 52.

- and Murray, S. (1956). Brit. med. F., 1, 187.

二 and Murray, s.

White, D., Haidar, G. A., and Reinhold, J. G. (1958). Clin. Chem., 4, 211.

Wild, A. E. (1961). Clin. Sci., 21, 221.

Witebsky, E. (1948). Blood, Special Issue No. 2, p. 66.

and Mohn, J. F. (1945). F. exp. Med., 82, 143.

Zipursky, A., Pollock, J., Chown, B., and Israels, L. G. (1963). Lancet, 2,493 .
It is of some importance that the obstetrician who is supervising the pregnancy of a patient with rhesus isoimmunization should be able to determine the severity of haemolytic disease affecting the infant in utero. At the present time the induction of labour before the expected date of delivery is the only measure which can be routinely offered to such a patient in an attempt to prevent the death of the foetus.

Walker and Neligan (1955) considered that $98 \%$ of infants born alive with haemolytic disease should survive if the treatment they received was adequate, and in 1958 Walker stated that with adequate care the neonatal mortality should be as low as 6 per 1,000. Unfortunately, a large number of stillbirths occur each year from haemolytic disease-500 in England and Wales (Lancet, 1958) - and in their series Walker and Murray (1956) reported a stillbirth rate of $10-15 \%$. Tragically, 7 to $8 \%$ of pregnancies in which antibodies had been detected for the first time ended in stillbirth, and it is primarily to prevent these stillbirths that prediction of the severity of the condition is required.

The methods of prediction available include the absolute level of the antibody titre in the maternal blood and the changes in this level, the previous history of the patient with regard to haemolytic disease in her children, the blood group and rhesus genotype of the patient's husband, and radiological examination. As none of these methods was entirely satisfactory, Bevis (1956) investigated the amount of "blood pigment " present in the liquor amnii, obtaining this liquor by inserting a needle through the anterior abdominal wall (Bevis, 1952). The liquor was then centrifuged and examined in a

* Senior Registrar, Simpson Memorial Maternity Pavilion, Royal Infirmary, Edinburgh ; Lecturer, Department of Obstetrics and Gynaecology, University of Edinburgh. spectrophotometer, the optical density being plotted against the wavelength at intervals between 360 and $700 \mathrm{~m} \mu$. The presence of a "bulge" from the expected "straight line" curve between 400 and $500 \mathrm{~m} \mu$ indicated whether or not the foetus was affected by haemolytic disease.

Walker (1957) used this test on 74 patients, and his prediction was correct in $91 \%$ of cases provided the test was carried out at 34 weeks and no distinction was made between " unaffected" and "mildly affected" infants. The actual severity of the condition was not predicted, nor was the management stated. Liley (1960) described the results obtained in 200 tests and reported the onset of premature labour in seven patients, and also two foetal deaths as a result of uterine infection. Cary (1960), McBride (1961), and Robertson (1961) were all impressed by the ease of "amniocentesis," and considered the procedure to be useful in patients with rhesus isoimmunization. Macbeth and Robertson (1961) found that the height of the optical density indicated the severity of the haemolytic disease in the foetus and indicated the optimum time for the induction of labour. Liley (1961) also was able to predict the severity.

Mackay (1961) performed one test on each of 233 patients and examined the liquor for "bilirubin staining." This determined the time of induction of labour. Walker and Jennison (1962) reported a further series of 156 patients with a $91 \%$ correct prediction rate. They did not find that chemical estimation of the bilirubin content of the liquor was satisfactory.

During the five years 1958-62 425 patients with rhesus isoimmunization attended the Simpson Memorial Maternity Pavilion of the Royal Infirmary of Edinburgh. Amniotic fluid was obtained on at least one occasion from 252 of these patients, and the results obtained are reported. 